\title{
1.07
}

\section{Audiências públicas: instrumentos em prol da democratização e concretização do direito à saúde}

Public Hearings: instruments for democratization and realization of the right to health

\section{Cândice Lisbôa Alves}

Advogada. Bacharel em Direito, Especialista, Mestre e Doutora em Direito Público. Professora do Curso de Direito do Centro Universitário Newton Paiva. Instrutora de Polícia da Polícia Militar de Minas Gerais. Belo Horizonte, Brasil.

Resumo: O presente artigo aborda as audiências públicas como instrumentos em prol da efetividade do direito à saúde. Discorre sobre a primeira audiência relacionada ao tema convocada pelo Supremo Tribunal Federal e, recentemente, as audiências públicas presididas pelos membros do Ministério Público Federal. Entende-se que a participação é instrumento essencial para a efetividade do direito à saúde, ressaltando-se, nesse sentido, a importância das audiências mencionadas.

Palavras-chave: audiências públicas; direito a saúde; concretização.

Keywords: public hearings; right to health; concreteness.

\section{Introdução}

O conceito de saúde é tema imbricado que remete a acalorados debates, com poucas conclusões ou definições precisas. Saúde, dependendo da área de atuação, tem significações diversas. Implica, de toda sorte, em serviços e utilidades, prestadas pelo particular ou pelo Estado, e, em quaisquer das hipóteses, é indispensável à dignidade humana.

Saúde é mais. No direito, assim como na realidade, é condição de possibilidade ou manutenção da vida, que deve ser protegida como bem fundamental, sem o qual nada existe ou faz sentido. Assim, parece ser possível concluir que o direito à saúde, em princípio, não pode sofrer restrições ou escavações sem uma justificativa plausível e consistente, ainda mais em um país como o Brasil, que traz no 
art. 196 da Constituição da República a obrigatoriedade de o Estado prestar os serviços de saúde, de forma universal e integral.

Não obstante a promessa constitucional, empecilhos consistentes e insistentes obstaculizam a concretização do direito à saúde. O primeiro deles diz respeito à definição de saúde - o que implica na indefinição sobre quais tratamentos estão acobertados pelo Estado. O segundo, à falta de orçamento suficiente para o adimplemento da integralidade garantida em relação ao direito. O terceiro, à falta de políticas públicas de saúde para cada uma das mazelas padecidas, bem os entreves decorrentes da rede burocrática de procedimentos e requerimentos necessários para a viabilização de alguns atos médicos e também para a dispensação de medicamentos não integrantes do RENAME (Rede Nacional de Medicamentos) ou não inseridos em protocolos clínicos adotados pelo SUS (Sistema Único de Saúde). O quarto, à ausência de conhecimento sobre direito à saúde, assim como à falta de órgãos públicos que exijam o cumprimento desse direito, e aqui não se está remetendo necessariamente à advogados públicos que promovem a judicialização da saúde, mas a órgãos que busquem a efetividade da saúde, de forma anterior à transferência do problema ao Poder Judiciário. Certo é que não basta ter direitos, é preciso poder gozar efetivamente dos mesmos. Este último item será o objeto de análise desse artigo: ou seja, a mobilização e integração de órgãos estatais em prol da efetividade do direito à saúde que parece estar acontecendo recentemente.

Como pano de fundo para a análise aqui proposta têm-se que a ausência de disponibilidade dos serviços de saúde - ou de prestação suficiente e eficiente - evidenciou-se de forma cristalina em relação aos portadores de neoplasias malignas, estimulando o Poder Legislativo a editar a Lei no 12.732, de 22 de novembro de 2012, para garantir tratamento dessa moléstia no prazo de até 60 (sessenta dias) do diagnóstico da doença. No art. 1ำ da lei, reafirmase a gratuidade do tratamento que deverá ser custeado pelo SUS. A vigência da legislação iniciou-se em 22 de maio de 2013, provocando uma grande angústia nos pacientes e nos setores públicos responsáveis pelos serviços que a legislação mencionou. 
É inegável que a rede pública de saúde não está equipada para garantir a efetividade da lei apontada. Neste sentido, visando à garantir a exigibilidade dos direitos inscritos na Lei, o Ministério Público da União, por determinação da 1a Câmara de Coordenação e Revisão, enviou ofício às suas regionais no sentido de que elas fomentassem audiências públicas convidando os setores competentes para juntos informarem as medidas que estavam sendo adotadas (ou seriam adotadas) para a implementação do tratamento imediato aos pacientes portadores de neoplasias malignas.

O ofício de convocação dos membros do Ministério Público Federal denominou esta ação de "dia de mobilização nacional pela efetividade do direito ao início do tratamento do câncer no SUS". A atitude do Ministério Público Federal é um reflexo da necessidade premente de participação popular para concretização dos direitos fundamentais, em especial do direito à saúde. Ela não deve ser interpretada como ato isolado, ao contrário, deve ser entendida como inserida em um contexto de mobilização em prol da efetivação dos direitos sociais que vem ocorrendo em diversos órgãos públicos, cada um deles com um objetivo diferenciado relacionado à sua atividade principal.

Diante da atitude do Ministério Público Federal, se buscará discutir a necessidade de participação para a concretização do direito à saúde, em especial tomando em conta a legislação mencionada. Anterior às audiências públicas promovidas pelo MPF ocorreu a audiência pública no Supremo Tribunal Federal (STF), em 2009, e paralelamente ocorreram outras, de menor proporção no país. É esta movimentação que interessa e é producente para a concretude que enfim se espera em relação à saúde pública.

\section{A invisibilidade no direito à saúde}

O direito à saúde, quando descumprido, dá margem a uma situação de invisibilidade que reflete a desigualdade da realidade brasileira. Aqueles que não têm acesso à saúde são desconsiderados, como se perdessem ou não possuíssem a prerrogativa conferida ao direito fundamental. São invisíveis para o Estado.

Os números são assustadores e cruéis e demonstram uma massa significativa de pessoas distantes do acesso à saúde. São pessoas fora do sistema, que com a negativa de atendimento dos serviços públicos acabam despidas da própria 
cidadania, no sentido de estarem afastadas das possibilidades de uma vida plena e digna. Para Jessé de Souza (2003), seriam os subcidadãos. Para Boaventura de Souza Santos, seriam o reflexo de uma separação abissal entre os dois lados da linha, entre os "deste lado" e os "daquele lado" (Santos, 2007, p.1), ou o reconhecimento de dois mundos que nem sempre se tocam. Para Bauman (2000, p. 29), representam um dos lados da vidraça. O perverso das descrições é que em todas elas está presente a situação de poder que, quando afastada, concretiza-se na privação de oportunidades, bens, serviços e, ao fim, até mesmo da dignidade humana. Diante dessa realidade abissal, urge fundamental a atuação do próprio Estado, em um de seus órgãos, para fomentar a inclusão, e cobrar dos demais entes públicos a re-inserção do excluído (ou inserção, nos casos em que a pessoa nunca tenha participado realmente dos rumos políticos do país, ou, por via diversa, nunca tenha se beneficiado dos direitos fundamentais expressos na Constituição da República). É nessa perspectiva que se analisa a audiência pública promovida pelo STF (Supremo Tribunal Federal) em 2009 e as audiências públicas promovidas pelo Ministério Público Federal no mês de maio de 2013, todas elas com o desiderato de fornecerem subsídios para a efetividade do atendimento de saúde à população, delimitando-se o papel do Estado.

Ainda que não se esmiúce a invisibilidade nesse artigo, se almeja evidenciar que todo o atendimento de saúde é burocratizado, necessitando de requerimentos e autorizações. Algumas vezes medicamento necessário para um caso específico não consta na listagem de dispensação fomentada pelo SUS, de forma que o Poder Executivo nega o requerimento do paciente sob a argumentação de que a dispensação deve pautar-se no princípio da legalidade. Também deve ser relembrado que os medicamentos de alto custo necessitam de procedimento administrativo para a respectiva dispensação, e, apenas são fornecidos se estiverem inseridos na listagem mencionada. Há ainda os casos relacionados a tratamentos experimentais, além dos tratamentos clínicos sem a chancela de inscrição de protocolo clínico inscrito no Sistema Público de Saúde. Grosso modo, é como se não houvesse tais situações. Todos os casos aqui relatados são pontos cegos do sistema, são a invisibilidade da realidade sanitária brasileira. Para defender pessoas que se adequam ás situações de invisibilidade do sistema tornou-se 
indispensável o manejamento de ações judiciais, sejam de tutela individual ou coletiva, por advogados particulares, defensorias públicas ou pelo ministério público estadual ou federal. Importante instrumento no sistema é a ação civil pública que pode ser manuseada tanto pelo ministério público quanto pela defensoria pública.

De toda forma, entende-se que os problemas mencionados deveriam ser solucionados no próprio órgão encarregado da prestação dos serviços de saúde, ou seja, no Poder Executivo e não por intermédio de ações judiciais. As audiências públicas são interessantes neste contexto, porque dão a oportunidade de se evitar a judicialização ou jurisdicização de uma questão que, em princípio, é política, muito embora não se limite à discricionariedade administrativa, de acordo com os critérios de oportunidade e conveniência somente. Entende-se que por meio das audiências públicas se democratize o acesso a saúde na medida em que problemas invisíveis ou que não querem ser vistos - são levados ao debate público, com chances de autoridades vestirem a bandeira dos excluídos e promoverem os atendimentos necessários. É nesse sentido que se acredita poder, em realidade, haver melhoria na saúde pública, com o engajamento político e a militância daqueles que sem atitude concretas de pressão são desconsiderados pelo Sistema.

\section{A audiência sobre saúde pública promovida pelo STF}

O Supremo Tribunal Federal promoveu a primeira audiência pública de saúde nos dias 27, 28 e 29 de abril e também nos dias 4, 6 e 7 de maio de 2009. Essa audiência foi motivada pelo número crescente de ações judiciais requerendo do Estado a concretização do direito à saúde, bem como das implicações administrativas e econômicas decorrentes das sentenças judiciais que tendiam ao deferimento de todos os requerimentos referentes às questões de saúde.

O Ministro Gilmar Mendes, relator da ação que deu origem à audiência, fez um retrospecto da problemática que envolve o direito à saúde, ressaltando que as constantes controvérsias jurisdicionais quanto aos requerimentos demandaram uma ação em que se discutissem os problemas mais relevantes em relação à saúde. Atenção especial veio no sentido de explicitar as tentativas dos órgãos executivos de furtarem-se ao cumprimento das ordens judiciais que determinavam o atendimento aos requerimentos de saúde, por meio de pedido de suspensão de liminares, 
cautelares e tutelas antecipadas - esta última situação foi a que ensejou a audiência pública.

Não se discutirá aqui a alegação de separação de poderes levantada pelos membros do Poder Executivo, porque se adota a premissa da vinculação de todos os Poderes na efetivação dos direitos fundamentais, dentre eles o da saúde. Isso significa que ante a inação dos Poderes competentes, o Judiciário adquire competência para determinar o cumprimento das obrigações inerentes aos Poderes Executivo e Legislativo. Pois bem, essa competência é supletiva ou subsidiária, apenas. Gilmar Mendes, inclusive, adverte que no caso do não cumprimento de dever imposto por política pública ou norma constitucional não se fala em judicialização, mas em cumprimento de direito subjetivo (STF, 2009, p. 16), situação que não dá ensejo sequer a negativa pelo Judiciário, sob pena de não cumprimento da norma constitucional formal ou material.

As conclusões da audiência pública não foram incisivas, como de fato não poderiam ser, diante da complexidade apresentada. Muitos pontos importantes foram debatidos, sem consenso estabelecido sobre os mesmos, mas com a profícua função de desvelamento de pontos cegos do sistema. É muito interessante observar que após a audiência criou-se um grupo de trabalho sobre a judicialização da saúde no Conselho Nacional de Justiça $(\mathrm{CNJ})$, qual seja, o Fórum Nacional do Judiciário para Assistência à Saúde (Braga, 2011, p.374). O Fórum elaborou Recomendação 31 (2010), de 30 de março de 2010, cujo objetivo foi o estabelecimento de medidas que deveriam ser adotadas pelos Tribunais estaduais e federais no sentido de subsidiar os magistrados em relação às decisões relacionadas à judicialização da saúde. Dentre as medidas, destaca-se o inciso I, a, que determina que até dezembro de 2010 deveriam ser celebrados convênios entre o Judiciário e os órgãos competentes visando a "disponibilizar apoio técnico composto por médicos e farmacêuticos para auxiliar os magistrados na formação de um juízo de valor quanto à apreciação das questões clínicas apresentadas pelas partes das ações relativas à saúde, observadas as peculiaridades regionais";

No texto da recomendação, outras medidas são sugeridas. Em especial, a vinculação das decisões judiciais a: prescrições médicas com determinações precisas e indicação do princípio ativo ao invés do nome comercial do 
medicamento; conferência sobre a presença dos medicamentos e tratamentos prescritos pertencerem à listagem do SUS e terem registro na ANVISA; não deferimento de tratamentos experimentais; inscrição do futuro beneficiário da prestação na política pública para tal fim no momento da sentença; criação pelas Corregedorias de Justiça de cursos relacionados ao direito sanitário, bem como vinculação de tal matéria nos concursos públicos e curso de formação dos recém-aprovados na magistratura.

Até hoje poucos Tribunais adotaram as recomendações sugeridas pelo CNJ, em especial em relação à criação de órgãos técnicos para subsidiar as decisões em relação ao direito à saúde. Em Minas Gerais, o Tribunal de Justiça firmou convênio com a Universidade Federal de Minas Gerais por meio da FUNDEP (Fundação de Desenvolvimento e Pesquisa) para elaborar estudos e avaliações sobre medicamentos discutidos nas ações judiciais. Tal ação ocorreu em 03 de agosto de 2012, e foi veiculada no site do Tribunal de Justiça de Minas Gerais (2013), sem, entretanto, anunciarem o resultado ou as modificações que o convênio projetou nas ações judiciais.

Algumas das sugestões oriundas da recomendação 31 do CNJ foram acatadas pelos magistrados. Houve, inclusive, a edição da Lei no 12.401, de 2011, (Brasil, 2011) que alterou a Lei $n^{\circ}$ 8.080, de 1990, dispondo sobre a assistência terapêutica e a incorporação de tecnologia em saúde no âmbito no SUS. Nessa egislação deve-se salientar a disposição do art. 19-T:

Art. 19-T. São vedados, em todas as esferas de gestão do SUS:

I - o pagamento, o ressarcimento ou o reembolso de medicamento, produto e procedimento clínico ou cirúrgico experimental, ou de uso não autorizado pela Agência Nacional de Vigilância Sanitária ANVISA;

II - a dispensação, o pagamento, o ressarcimento ou o reembolso de medicamento e produto, nacional ou importado, sem registro na Anvisa. (Brasil, 2011).

O interessante desta disposição é a reafirmação da necessidade de aprovação pela Anvisa das medicações dispensadas pelo SUS. Não se ignora a necessidade de seriedade em relação à incorporação de medicação ou sua distribuição pelo SUS, entretanto, não se pode esquecer que os procedimentos referentes a essas situações são excessivamente demorados, e, enquanto não conclusos, os adoentados padecem revezes físicos que podem eclodir no falecimento. 
Outro ponto interessante a ser ressaltado é que na ação que deu ensejo à audiência pública de saúde, a STA-175 (Supensão de tutela antecipada), o MPF requereu medicação não registrada pela Anvisa e a mesma foi deferida pelo magistrado a quo. Iniciou-se o procedimento clínico solicitado, mas o Estado não satisfeito com o deferimento da medida interpôs recurso confirmando-se a sentença inicial na apelação, e também na STA-175 junto ao STF. Ou seja, o STF reconheceu a excepcionalidade de algumas demandas. Posicionou-se no sentido de que quando houver elementos que comprovem a segurança da medicação, as medidas judiciais que garantam o atendimento à saúde devem ser deferidas ao paciente, principalmente quando não houver outra alternativa medicamentosa. No caso que deu origem à discussão, a medicação era reconhecida como segura pela União Europeia, muito embora no Brasil ainda não fosse autorizada pela Anavisa ou incorporada pelo SUS. Essa discussão sobre dispensação medicamentosa é séria e controversa, e não se encerra na simples proibição de custeio pelo Estado por falta de registro na Anvisa, tanto que o MPF colocou em sua pauta de discussão sobre saúde a necessidade da atuação institucional do órgão em prol da dispensação de medicamentos de alto custo, bem como no atendimento de doentes cardíacos cujo tratamento recomendado não está autorizado pela ANS (Agência Nacional de Saúde), como se verá no item seguinte.

\section{As audiências públicas sobre a Lei no 12.732, de 2012, promovidas pelo Ministério Público Federal}

O Ministério Público Federal ciente da necessidade de sua atuação para a concretização do direito à saúde criou o Grupo de Trabalho Nacional denominado GT-Saúde através da Portaria 02/2013, da 1a Câmara de Coordenação e Revisão, aos 05 de fevereiro de 2013.

O objetivo do GT-Saúde é detectar os entraves e dificuldades na prestação da saúde pública, bem como estudar os instrumentos legais e políticos a serem adotados pelo Ministério Público Federal na luta pela concretização da saúde. Na portaria citam-se especificamente três situações-problemas que requerem atuação próxima do MPF: a primeira atine à dispensação de medicação de alto custo pelo Estado; a segunda diz respeito à Lei 12.732/2012, que cuida do 
atendimento em até 60 (sessenta) dias para os portadores diagnosticados de neoplasia maligna; a terceira, por sua vez, menciona a atividade necessária à inclusão na ANS para custeio pelo SUS de:

[...] novas técnicas de tratamento dos pacientes acometidos de moléstias do coração; entre as quais, a mencionada na solicitação feita, em novembro de 2012, pela Sociedade Brasileira de Hemodinâmica e Cardiologia Intervencionista ( $\mathrm{SBHCl}$ ), ou seja, a de Implante Transcateter de Valva Aórtica (TAVI) já aprovada pelo Conselho Federal de Medicina como tratamento adequado para os enfermos portadores de estenose valvar aórtica severa, notadamente idosos ou indivíduos que não possam submeter-se à cirurgia de troca valvar aórtica convencional (Portaria 02/2013, 2013).

Com as descrições presentes no art. 1ํㅜㄹ parágrafo único, da portaria fica claro o reconhecimento pelo Parquet federal de algumas das deficiências referentes à prestação da saúde pública. Percebe-se que a primeira delas diz respeito à dispensação de medicamentos de alto custo, a maior causa das ações de judicialização da saúde; a segunda diz respeito à Lei nova que prevê o atendimento aos portadores de câncer, isto porque o Ministério Público Federal sabe da impossibilidade estatal de cumprimento pelo Estado do prazo estabelecido na Lei. O último dos motivos é, também, o reconhecimento da incompatibilidade entre a necessidade de um paciente por tratamento determinado quando este não se constitui acobertado por protocolo clínico, impedindo-se, pela legislação nacional, o custeio por parte do Estado.

Todas as situações são graves e sérias, porém neste trabalho interessa a segunda, pois foi ela que deu ensejo à mobilização nacional do MPF, ocorrendo no dia 22 de maio de 2013 audiências públicas em vários Estados do país. Para as audiências públicas foram convocados secretários de saúde estaduais, municipais, diretores de hospitais públicos e também alguns particulares que prestam serviços aos SUS, em especial nos tratamentos das neoplasias. O objetivo foi apurar a estruturação dos órgãos responsáveis pelos serviços de saúde atinentes às neoplasias malignas, visando com isto delimitar um plano de atuação para o caso de descumprimento da Lei $\mathrm{n} \times 12.732$, de 2012.

Inicialmente, no documento convocatório para as audiências públicas, ficou consignada a possibilidade de ações de improbidade administrativa para o caso de a Lei não ser cumprida no prazo avençado ou de forma satisfatória. 
O interessante desta movimentação é o reconhecimento por parte do Ministério Público que sem sua atuação efetiva, bem como dos demais órgãos estatais, a saúde pública não será prestada de forma adequada. Ou seja, não se acredita que a mera normatização seja suficiente, tampouco que ações isoladas resolvam o problema, ou ainda, que a judicialização da saúde seja a melhor opção. O ideal é a comunicação dos órgãos responsáveis e o adimplemento espontâneo das obrigações estatais.

A atuação do MPF representa, de outro giro, papel crucial como estímulo positivo para a efetividade do direito à saúde, isto porque ele tem competência para firmar TAC (termo de ajustamento de conduta) com os órgãos que descumprirem a legislação. Há ainda a possibilidade de o Parquet intentar ação civil pública e ação de improbidade administrativa. Ou seja, o chamado para discutir o problema por parte do MPF é mais que um simples convite, é um alerta sobre consequências posteriores. Ainda deve-se mencionar que como essa atitude é nova, e tendo em vista a criação de um GT nacional, o MPF parece sinalizar no sentido de que a ação não é vã, em outras palavras, eles irão determinar politicamente que todos os órgãos fiscalizem e tomem as medidas legais cabíveis.

Em relação à efetividade do direito à saúde, a atuação do MPF é uma aliança imprescindível, que parece prometer frutos bons e necessários para aqueles que padecem de enfermidades graves ou daquelas enfermidades que estão imersas em burocracias infindáveis para que o SUS custeie o atendimento ou o fornecimento de medicação e/ou tratamento.

\section{Conclusão: a concretização da saúde requer participação}

As audiências públicas sobre saúde têm se mostrado como instrumentos aptos à promoção de discussões sobre as precariedades do sistema público de saúde. Mais, elas são o reconhecimento de que nessa seara não basta legalidade, e sim bom senso e equilíbrio.

As normas sobre saúde pública estão sendo criadas em uma velocidade crescente, o que dificulta a incorporação de seu conteúdo pelos gestores públicos, que ora recebem autorização para negarem atendimento médico se 
não há incorporação no sistema do SUS, ora se veem compelidos a se equiparem rapidamente para fomentarem tratamento a neoplasias malignas, ora recebem ordens judiciais determinando o custeio de alguns tratamentos. Há uma avalanche legislativa, jurisdicional e pouca sintonia entre os gestores políticos.

Lado outro, a população permanece necessitando dos serviços do Estado, e cada vez mais. Então, é necessário repensar papéis, bem como atuações dos atores sociais envolvidos na gestão da saúde pública assim como na fiscalização do cumprimento dessas atividades.

O que se sugere diante de tantos descompassos é a participação popular. As audiências públicas são importantes, mas a ação individual de quem padece da doença é elementar, porque é por meio do comparecimento ao Ministério Público, Defensoria Pública ou mesmo por intermédio de advogado particular que o Estado é chamado a agir, e, em certa medida, reafirma sua consciência sobre as mazelas sanitárias.

Não basta esperar. Não há mágica no sistema. É no embate e no calor das reivindicações que a saúde coloca-se na esfera pública de discussão, e assim há a possibilidade de algo ser feito em prol da efetividade que tanto se aguarda.

\section{Referências}

BARROSO, Luís Roberto. A doutrina brasileira da efetividade. In: BARROSO, Luís Roberto. Temas de Direito Constitucional. 2.ed. Tomo III. Rio de Janeiro: Renovar: 2008, p.61-78.

BARROSO, Luís Roberto. Constituição, democracia e supremacia judicial: direito e política no Brasil contemporâneo. Disponível em:< http://www.Irbarroso.com.br/pt/noticias/constituicao_democracia_e_supremacia_ judicial_11032010.pdf>. Acesso em: 12 ago. 2010.

BRASIL. Anvisa. Medicamentos. Disponível em: <http://portal.anvisa.gov.br/wps/content/Anvisa+Portal/Anvisa/Inicio/Medicament os> Acesso em: 13 mar. 2013.

BRASIL. Anvisa. Medicamentos genéricos: oriente-se. Brasília: 2002. Disponível em: <http://portal.anvisa.gov.br/wps/wcm/connect/a09ae180483c0adca421af0d8b42 75ce/genericos_cartilha.pdf?MOD=AJPERES>. Acesso em: 13 mar. 2013.

BRASIL. Conselho Nacional de Justiça. Recomendação no 31, de 30 de março de 2010. Recomenda aos Tribunais a adoção de medidas visando a melhor subsidiar os magistrados e demais operadores do direito, para assegurar maior eficiência na solução das demandas judiciais envolvendo a assistência à saúde.(Publicado no DJ-e 
no 61/2010, em 07/04/2010, p. 4-6). Disponível em: <http://www.cnj.jus.br/atosadministrativos/atos-da-presidencia/322-recomendacoes-do-conselho/12113recomendacao-no-31-de-30-de-marco-de-2010>. Acesso em: 12 nov. 2012.

BRASIL. Lei 12.401, de 28 de abril de 2011. Altera a Lei no 8.080, de 19 de setembro de 1990, para dispor sobre a assistência terapêutica e a incorporação de tecnologia em saúde no âmbito do Sistema Único de Saúde - SUS. Diário Oficial da União, Brasília, 29 abr. 2011. Disponível em:< http://www.planalto.gov.br/ccivil_03/_Ato2011-2014/2011/Lei/L12401.htm> Acesso em: 06 jun. 2011.

BRASIL. Lei 12.732, de 22 de novembro de 2012. Dispõe sobre o primeiro tratamento de paciente com neoplasia maligna comprovada e estabelece prazo para seu início. Diário Oficial da União, Brasília, 22 nov. 2012. Disponível em:< http://www.planalto.gov.br/ccivil_03/_ato2011-2014/2012/lei/l12732.htm>

Acesso em: 06 jun. 2013.

BRASIL. Supremo Tribunal Federal. STA175/CE. Rel. Min. Gilmar Mendes, 2009. Disponível em: <http://www.stf.jus.br/portal/jurisprudencia/listarJurisprudencia.asp?s1=\%28STA $\% 24 . S C L A .+E+175 . N U M E . \% 29 \&$ base=baseMonocraticas $>$ Acesso em: 10 out. 2010.

CANOTILHO, José Joaquim Gomes. Direito Constitucional e Teoria da Constituição. 7.ed. Coimbra: Almedina, 2003.

BRASIL. Ministério Público Federal. Portaria no 02/2013 - 1aㅡ CCR/MPF, de 05 de fevereiro de 2013. 1 a Câmara de Coordenação e Revisão. Dispõe sobre a criação de Grupo de Trabalho na 1a Câmara de Coordenação do Ministério Público Federal com a finalidade de estimular o aperfeiçoamento da prestação de serviços na área da saúde e do atendimento médico-hospitalar, designando os integrantes. Disponível em: < http://sbhci.org.br/tavi/wpcontent/uploads/2013/03/Portaria-02-2013-1CCR.pdf> Acesso em: 05 jun. 2013.

BAUMAN, Zygmunt. Em busca da política. Rio de Janeiro: Zahar, 2000.

HESSE, Konrad. A força normativa da Constituição. Trad. Gilmar Ferreira Mendes. Porto Alegre: Sergio Antonio Fabris Editor, 2002.

HESSE, Konrad. Elementos de Direito Constitucional da República Federal da Alemanha. Trad. Luís Afonso Heck. Porto Alegre: Sergio Antonio Fabris Editor, 1998.

KRELL, Andreas J. Direitos sociais e controle judicial no Brasil e na Alemanha: os (dês)caminhos de um direito constitucional "comparado". Porto Alegre: Sergio Antonio Fabris Editor, 2002.

MINAS GERAIS. Tribunal de Justiça. Assessoria de Comunicação Institucional. Saúde: convênio vai aprimorar decisões. Veiculado em 03/08/2012. Disponível em: <http://ftp.tjmg.jus.br/anexos/nt/noticia.jsp?codigoNoticia=48738> Acesso em: 10 jan. 2013.

SANTOS, Boaventura de Sousa. Para além do pensamento abissal: das linhas globais a uma ecologia de saberes. Novos Estudos-CEBRAP, (79):71-94, 2007. 
Anais dos III Congresso Iberoamericano de Direito Sanitário / II Congresso Brasileiro de Direito Sanitário

SOUZA, Jessé. A construção social da subcidadania: para uma sociologia política da modernidade periférica. Belo Horizonte: Ed. UFMG, Rio de Janeiro: IUPERJ, 2003. 